\title{
A New Approach of Morgan-Voyce Polynomial to Solve Three Point Boundary Value Problems
}

\author{
Bushra Esaa Kashem \\ bushra_eesa@yahoo.com, 100047@uotechnology.edu.iq \\ Department Applied Sciences, University of Technology, Baghdad, Iraq.
}

\begin{abstract}
In this paper, a new procedure is introduced to estimate the solution for the three-point boundary value problem which is instituted on the use of Morgan-Voyce polynomial. In the beginning, Morgan-Voyce polynomial along with their important properties is introduced. Next, this polynomial with aid of the collocation method utilized to modify the differential equation with boundary conditions to the algebraic system. Finally, the examples approve the validity and accuracy of the proposed method.
\end{abstract}

Keywords: Morgan-voyce, three-point boundary value problem, collocation method, approximation method.

\section{Introduction}

The three point boundary value problem belongs to the seeming nonlocal or multipoint boundary value problem. This local boundary value problem has a major role in physics, engineering and many phenomena in applied mathematical. An amount of research has been studying the three-point boundary value problem, for example, the positive solution [1], existence and stability [2], discrete first order [3], and variational principle [4].

In this study, we consider the linear three point boundary value problem is:-

$\ddot{D} Z(x)+F(x) Z(x)=G(x)$ with $Z(a)=Z(b)=A$ and $\dot{Z}(c)=B \quad x \in(a, b)$

Where F, $G$ is a continuous function. a, b, c $\in R$. A, B real constant.

The main purpose of this work is to modify a new algorithm for an approximate solution to three point boundary value problems based on the special case of Morgan-Voyce polynomial. The properties and the method for using are explored. This method decreased the differential equation with its initial and boundary conditions to a system of algebraic equations in the unknown expand coefficients.

\section{Morgan-Voyce polynomial}

Diametrical polynomial Morgan-Voyce which is introduced recently in 1959 [5] at was used in many interesting papers such as, Functional integro [6], pantograph equation [7], differential-difference equation [8], and nonlinear ordinary differential equation [9]. 
Ibn Al-Haitham Journal for Pure and Applied science https://doi.org/10.30526/2021.IHICPAS.2654

The Morgan-Voyce polynomials $M_{n}(x)$ defined by:- [10]

$M_{n+2}(x)=M_{n+1}(x)-M_{n}(x)$

With $M_{0}(x)=2, M_{1}(x)=x+2$

and explicit formulation $(n \geq 1, n>k)$

$M_{n}(x)=\sum_{k=0}^{n-1} \frac{2 n}{n-k}\left(\begin{array}{c}n+k-1 \\ n-k-1\end{array}\right) x^{k}+x^{n}$

on other hand, by using eq.(2) \& eq.(3) the first seven Morgan-Voyce polynomials are given:

$$
\begin{aligned}
& M_{0}(x)=2 \\
& M_{1}(x)=x+2 \\
& M_{2}(x)=x^{2}+4 x+2 \\
& M_{3}(x)=x^{3}+6 x^{2}+9 x+2 \\
& M_{4}(x)=x^{4}+8 x^{3}+20 x^{2}+16 x+2 \\
& M_{5}(x)=x^{5}+10 x^{4}+35 x^{3}+50 x^{2}+25 x+2 \\
& M_{6}(x)=x^{6}+12 x^{5}+54 x^{4}+112 x^{3}+105 x^{2}+36 x+2 \\
& M_{7}(x)=x^{7}+14 x^{6}+77 x^{5}+210 x^{4}+294 x^{3}+196 x^{2}+49 x+2
\end{aligned}
$$

3- Important Properties of Morgan-Voyce polynomial: [11,12]

1- Connection with Chybechev and Lucas polynomial $T_{n}(x), L_{n}(x)$

$$
\begin{gathered}
M_{n}(x)=2 T_{n}\left(\frac{x+2}{2}\right) \\
M_{n}\left(x^{2}\right)=L_{2 n}(x)
\end{gathered}
$$

\section{2- Orthogonality}

$M_{n}(x)$ is an orthogonal polynomial over $[0,-4]$ with weight function $\frac{1}{\sqrt{4-(x+2)^{2}}}$

\section{Integration}


Ibn Al-Haitham Journal for Pure and Applied science https://doi.org/10.30526/2021.IHICPAS.2654

$$
\begin{aligned}
& \int_{-4}^{0} M_{2 n+1}(x) d x=0 \\
& \int_{-4}^{0} M_{2 n}(x) d x=\frac{8}{(2 n+1)(2 n-1)}
\end{aligned}
$$

\section{4-Zeros}

$M_{n}(x): x_{r}=-4 \sin ^{2}\left[\frac{2 r-1}{2 n} * \frac{\pi}{2}\right], \quad r=1,2, \ldots, n$

\section{Morgan-Voyce Collocation Method}

In this section, the solution of three-point boundary value problem can be abstracted by the following steps.

\section{Step 1}

The function $\ddot{Z}(x)$ in eq.(1) developed approximately using Morgan-Voyce polynomial:-

$\ddot{Z}(x)=\sum_{i=0}^{n} C_{i} M_{i}(x)$

\section{Step 2}

Integrating eq.(4) twice from $0 \mathrm{t} 0 \mathrm{x}$ depending the boundary condition to get :-

$Z(x)=Z(0)+\dot{Z}(0) x+\iint_{0}^{x} \sum_{i=0}^{n} C_{i} M_{i}(x)$

\section{Step 3}

Substituting the boundary condition into eq.(5) to reduce the Morgan-Voyce coefficient differential equation.

\section{Step 4}

Rewriting eq.(1) by substituted eq.(5) \&(4) to get

$\sum_{i=0}^{n} C_{i} M_{i}(x)+F(x)\left[Z(0)+\dot{Z}(0) x+\iint_{0}^{x} \sum_{i=0}^{n} C_{i} M_{i}(x)\right]=G(x)$

\section{Step 5}

By consider the collocation point $x_{j}=\frac{j-0.5}{2 n} \quad \mathrm{j}=1,2,3, \ldots$ can be resulting algebraic system which is solved to find the unknown coefficient $M_{i}$.

\section{Step 7}

For more information about the Conference please visit the websites: 
Ibn Al-Haitham Journal for Pure and Applied science https://doi.org/10.30526/2021.IHICPAS.2654

Substituted the calculated coefficients into eq.(5). The solution for eq.(1) will be obtained.

\section{Examples Illustrations:-}

For showing the accuracy and activity of our approximate method, we consider the following examples.

\section{Example (1):}

$$
\ddot{Z}-12 x^{-2} Z=0 \quad Z(1)=Z(-1)=1, \quad Z(0)=\dot{Z}(0)=0
$$

Exact solution $\mathrm{x}^{4}$

For assume $\ddot{Z}(x) \cong \sum_{i=0}^{4} C_{i} M_{i}(x)$

by integrating eq.(8) twice time and applying the steps studied in section(3), the approximate coefficient will be

$\mathrm{C}_{0}=36, \mathrm{C}_{1}=-48, \mathrm{C}_{2}=12, \mathrm{C}_{3}=\mathrm{C}_{4}=0$.

Applying the approximate coefficient into eq.(8), we obtain the exact solution $Z(x) \cong x^{4}$

\section{Example (2):}

$$
\ddot{Z}-Z=\left(4 x^{6}+12 x^{2}\right) e^{x^{2}} \quad Z(1)=Z(-1)=e^{1}, \quad Z(0)=\dot{Z}(0)=0
$$

Exact solution $x^{4} e^{x^{2}}$

Assume that $\ddot{Z}(x) \cong \sum_{i=0}^{6} C_{i} M_{i}(x)$

by applying the same method and solve a system of equations we approximate the solution.

Table 1 reflects the comparison between the approximate solution with the exact solution and absolute error.

Table 1

\begin{tabular}{|c|c|c|c|}
\hline $\mathbf{x}$ & approximate & Exact & Absolute error \\
\hline $\mathbf{- 1}$ & 2.718282 & 2.718282 & 0 \\
\hline $\mathbf{- 0 . 7 5}$ & 0.555381 & 0.555310 & 0.000071 \\
\hline $\mathbf{- 0 . 5}$ & 0.080242 & 0.080252 & 0.00001 \\
\hline $\mathbf{- 0 . 2 5}$ & 0.004157 & 0.004158 & 0.0000001 \\
\hline
\end{tabular}

For more information about the Conference please visit the websites: 
Ibn Al-Haitham Journal for Pure and Applied science https://doi.org/10.30526/2021.IHICPAS.2654

\begin{tabular}{|c|c|c|c|}
\hline $\mathbf{0}$ & 0 & 0 & 0 \\
\hline $\mathbf{0 . 2 5}$ & 0.004157 & 0.004158 & 0.0000001 \\
\hline $\mathbf{0 . 5}$ & 0.080242 & 0.080252 & 0.00001 \\
\hline $\mathbf{0 . 7 5}$ & 0.555381 & 0.555310 & 0.000071 \\
\hline $\mathbf{1}$ & 2.718282 & 2.718282 & 0 \\
\hline
\end{tabular}

\section{Example (3):}

$$
\begin{gathered}
\ddot{Z}-\frac{1}{x} \dot{Z}+Z=(4 x+1) e^{x^{2}}+x^{2} \quad Z(1)=Z(-1)=1+e^{1}, Z(0)=1, \\
\dot{Z}(0)=0
\end{gathered}
$$

Exact solution $x^{2}+e^{x^{2}}$

let $\ddot{Z}(x) \cong \sum_{i=0}^{8} C_{i} M_{i}(x)$

the comparison between the approximate and exact solution are showing in Table 2.

Table 2

\begin{tabular}{|c|c|c|c|}
\hline $\mathbf{X}$ & approximate & Exact & Absolute error \\
\hline $\mathbf{- 1}$ & 3.718282 & 3.718282 & 0 \\
\hline $\mathbf{- 0 . 8}$ & 2.536470 & 2.536481 & 0.000011 \\
\hline $\mathbf{- 0 . 6}$ & 1.793318 & 1.793329 & 0.000011 \\
\hline $\mathbf{- 0 . 4}$ & 1.333511 & 1.333511 & 0.000000 \\
\hline $\mathbf{- 0 . 2}$ & 1.080812 & 1.080811 & 0.000001 \\
\hline $\mathbf{0}$ & 1 & 1 & 0.000001 \\
\hline $\mathbf{0 . 2}$ & 1.080812 & 1.080811 & 0.000000 \\
\hline $\mathbf{0 . 4}$ & 1.333511 & 1.333511 & 0.000011 \\
\hline $\mathbf{0 . 6}$ & 1.793318 & 1.793329 & 0.000011 \\
\hline $\mathbf{0 . 8}$ & 2.536470 & 2.536481 & 0 \\
\hline $\mathbf{1}$ & 3.718282 & 3.718282 & \\
\hline
\end{tabular}

For more information about the Conference please visit the websites: 


\section{Conclusion}

In this article, a new general formula for Morgan-Voyce polynomial collocation method is employed to solve the three-point boundary value problems. The approached plane is tested by some examples and the results are satisfied in comparison with approximate with existing.

\section{References}

1. Yang, C. Positive Solutions for a Three-Point Boundary Value Problem of Fractional QDifference Equations. Symmetry. 2018, 10(9), 358; doi:10.3390/sym10090358.

2. Ali, Z.; Zada, A.; Shah, k. Existence and Stability Analysis of Three Point Boundary Value Problem. International Journal of Applied and Computational Mathematics, 2017, 3(1), 651664. doi:101007/s40819-017-0375-8.

3. Mohamed, M. ; Thompson, H.; Jusoh M. Discrete First-Order Three-Point Boundary Value Problem. Journal of Mathematics Research, 2019, 1, 2. doi:10.5539/jmr.v1n2p207.

4. Liu H.; He J.; Li Z. Variational principle for a three-point boundary value problem. J. Nonlinear Sci. Appl. 2016, 9(8):5169—5174. doi:10.22436/jnsa.009.08.02.

5. Morgan-Voyce,A.Ladder-Network Analysis Using Fibonacci Numbers. in IRE transactions on Circuit Theory.1959, 6, 3, 321-322, , doi: 10.1109/TCT.1959.1086564.

6. Özel M, K; Kürkçü, Ö; Sezer M. Morgan-Voyce matrix method for generalized functional integro-differential equations of Volterra type. Journal of Science and Arts ,2019, 47 (2): 295310. Available from: https://search.proquest.com /openview/04dd41f26209638 eae2f4f2 486d359d7/1 ?pq-origsite $=$ gscholar $\&$ cbl $=105793$.

7. İlhan, Ö.An Improved Morgan-Voyce Collocation Method for Numerical Solution of Generalized Pantograph Equations. Journal of Scientific and Engineering Research, 2017, 4(10):320-332. Available from: http://oaji.net/articles/2017/4834-1525935151.pdf.

8. Türky1lmaz, B; Gürbüz, B; Sezer, M. Morgan-Voyce Polynomial Approach for Solution of High-Order Linear Differential-Difference Equations with Residual Error Estimation. Düzce University, Journal of Science and Technology, 2016, 4 (1), 0-0. Available from :https: // dergipark org.tr/tr/pub/dubited/issue/24381/258462.

9. Tarakçi, M.,;Özel, M.; Sezer, M. Solution of nonlinear ordinary differential equations with quadratic and cubic terms by Morgan-Voyce matrix-collocation method. Turkish Journal of Mathematics, 2020, 44, 906-918,doi:10.3906/mat-1908-102.

10.Swamy ,M.; Bhattacharyya ,B.A Study of Recurrent Ladders Using the Polynomials Defined by Morgan-Voyce. in IEEE Transactions on Circuit Theory, 1967, 14, 3, 260-264, doi: 10.1109/TCT.1967.1082705.

11. Horadam A.F.New Aspects of Morgan-Voyce Polynomials. In: Bergum G.E., Philippou A.N., Horadam A.F. (eds) Applications of Fibonacci Numbers. Springer, Dordrecht.1998. doi:10.1007/978-94-011-5020-0_20. 
Ibn Al-Haitham Journal for Pure and Applied science https://doi.org/10.30526/2021.IHICPAS.2654

12. Swamy, M. RISING DIAGONAL POLYNOMIALS ASSOCIATED WITH MORGANVOYCE POLYNOMIALS. Fibonacci Quarterly, 200,)38(1), AMS Classification Available from: https://www..fq.math.ca/Scanned/38-1/swamy2.pdf 0. 